\title{
Por arte se ha de regir el amor. El proceso de recuesta según Ximénez de Urrea
}

\author{
Valentín Núñez Rivera \\ Universidad de Huelva
}

Uno de los pasajes de Penitencia de amor que más ha despertado el interés de la crítica ha sido la definición de la obra que hace el propio Ximénez de Urrea en el prólogo de la misma, llamándola con razón «esta arte de amores». Por lo común, una caracterización tan ajustada al texto se ha extrapolado a otros más o menos adyacentes, que, eso sí, tratan siempre del amor y sus circunstancias. ${ }^{1}$ En lo que respecta, no obstante, a las ficciones sentimentales existe, desde luego, la objeción de que todas ellas se denominan Tractados en los títulos o en las piezas prologales y este concepto supera semánticamente al de las artes de amores, desde el momento en que no todos han de serlo necesariamente. De cualquier modo, dejando a un lado la posibilidad de aplicar o no el concepto a otras obras circundantes, Urrea sabe muy bien lo que se hace cuando sostiene que su propuesta específica se trata de un arte de amar en toda regla. Y por eso lo confirma no muchas páginas después, explicando con más detalle el alcance de su definición previa. En la primera conversación de Darino, el caballero enamorado, con sus dos criados y consejeros, uno de ellos intenta convencerlo de que las «diligencias y mañas» ablandan cualquier cosa por fuerte que sea en un principio, especialmente en lo tocante a los casos de amor. Entonces, Renedo echa mano de un conocidísimo y recurrente pasaje del Ars amatoria de Ovidio (I, 3-4) para ejemplificar esa máxima, traduciendo así de su cosecha: 
Que como dize Ovidio, por arte de los remos y velas van las fustas por la mar, por arte son ligeros los carros y carretas y por arte se a de regir el amor, que por muy grave que sea verná a la razón. El cavallo rezia cosa es quando va corriendo, mas con el freno lo detienen (77). ${ }^{2}$

Con esta cita Ximénez de Urrea se integra en la tradición de las artes de amar, puesto que el fragmento ya aparece glosado, por ejemplo, en las enseñanzas de Venus a don Melón en el Libro de buen amor, a partir del Pamphilus de amore. ${ }^{3}$

Así pues, esa naturaleza erotodidáctica condiciona todas las particularidades de la obra, desde su propia enunciación, a la estructura dramática. Y también se extiende a la concepción y actuación de los personajes, sus relaciones, y, en fin, al propio proceso de recuesta amorosa, a través del intercambio epistolar y de los encuentros furtivos entre Darino y Finoya. Además, la mayor parte de estos componentes aparecen recogidos de modo explícito, es decir, de tal forma que tanto el autor como los personajes se refieren a ellos desde una perspectiva autorreflexiva. ${ }^{4} \operatorname{Sin}$ ir más lejos, la aseveración del prólogo ya comentada se refiere a su conformación discursiva. ${ }^{5}$ Dice Urrea: «esta arte de amores está ya muy usada en esta manera por cartas y por çenas» (71). En definitiva, las pautas del arte de amores se evidencian en la Penitencia desde un punto de vista teórico, haciendo referencia a las fuentes y los modelos previos, y con una plasmación práctica de las consabidas estrategias. El primer aspecto corresponde fundamentalmente al contenido de los parlamentos de Renedo y Angis, los criados confidentes; y la segunda, al propio caso de amores entre Darino y Finoya.

2. Todas las citas van por la edición de Manuel Ximénez de Urrea, Penitencia de amor, ed. Domingo Ynduráin, Madrid, Akal, 1996. 103.

3. Pamphilus de amore, ed. L. Rubio y T. González Rolán, Barcelona, Bosch, 1991, pp. $95-$

4. La autorreflexividad es una de las características de la ficción sentimental señaladas últimamente por la crítica. Por ejemplo, E. Michael Gerli, «Metafiction in Spanish Sentimental Romances", en The Age of Catholic Monarchs; 1474-1516: Literary Studies in memory of Keith Whinnom, Liverpool University Press, 1989, pp. 57-63. También, V. Blay Manzanera, «Metaliteratura y reflexividad en la ficción sentimental: La primera generación", Anuario Medieval, vi (1994), pp. 39-74.

5. Sobre el particular he tratado en «Penitencia de amor en la tradición sentimental (Porque todo lo que es ha sido)", Bulletin of Spanish Studies, LXxxiII, 4 (2006), pp. 481-505. Este trabajo supone la base conceptual de la que parten las reflexiones presentes. 


\section{Un arte de amores}

Comparando con la ficción sentimental anterior, el proceso de amores ${ }^{6}$ de la Penitencia resulta bastante desarrollado, con una peripecia continuada, entre otras cosas porque combina rasgos de los tratados de Flores o San Pedro con la Tragicomedia de Calisto y Melibea, un hibridismo que no ha pasado inadvertido para la crítica. ${ }^{7}$ Pero este desarrollo del caso de amor no tiene una finalidad en sí mismo, sino que está supeditado al modelo del arte de amar. Esto quiere decir que se propone sobre todo como ejemplo paradigmático del procedimiento de los amadores y las amadas en el código cortés. ${ }^{8}$ Por eso se ha hablado de cierto mecanicismo en la trama de la obra. Lo que ocurre es que el proceder de Darino y las reacciones de Finoya son siempre las esperables, las que vienen dándose en los especímenes de la tradición sentimental y en la erotodidaxis desde época clásica. Las alusiones a esta suerte de determinismo de los acontecimientos, no ya a causa del destino o las leyes de natura, que también los condicionan, ${ }^{9}$ sino por obra del seguimiento de unos patrones consabidos, constituye uno de los temas recurrentes a lo largo del texto. Todos los personajes son lectores internos, conscientes de los procesos amorosos de la tradición. ${ }^{10}$ Conocen el catálogo al uso de mujeres culpables (84) o de hombres pecadores (113). ${ }^{11}$ Darino ha sido lector de casos de amores paralelos al suyo. Renedo le dice, por ejemplo: "Y en estos casos de amores, como tú, señor, mejor sabes, que as leýdo más que yo...» (77). Él mismo

6. Resulta fundamental al respecto, José Luis Canet, «El proceso de enamoramiento como elemento estructurante en la ficción sentimental", en Historias y ficciones: coloquio sobre la literatura del siglo XV», ed. R. Beltrán, J. L. Canet y J. L. Sirera, Valencia, Universitat de Valencia, Departament de Filologia Espanyola, 1992, pp. 227- 39. Téngase en cuenta además, Valentín Núñez Rivera, "Los casos de amor desde Juan de Flores hasta Celestina. Entre terceros y mezcladores» en Homenaje a Klaus Wagner, ed. Piedad Bolaños et al., Sevilla, Universidad (en prensa).

7. Desde M. Menéndez Pelayo, Orígenes de la novela, III, ed. Enrique Sánchez Reyes, Edición Nacional de las Obras Completas de Menéndez Pelayo, Madrid, CSIC, 1943. Añádase R. Foulché Delbosc, "La Penitencia de amor de Pedro Manuel de Urrea», Revue Hispanique, 9 (1902), pp. 200-215. Además mis reflexiones en «Penitencia de amor en la tradición sentimental...».

8. La enseñanza ex contrario es una de las señas de identidad de las artes de amores, puesto que todas ellas son a su vez ejemplo de la reprobatio amoris.

9. Esta perspectiva del texto la he estudiado por mi parte en «Penitencia de amor en la tradición sentimental...», pp. 500-505.

10. Sobre esa cuestión ha trabajado Barbara F. Weissberger, desde su «Authors, Characters and Readers in Grimalte y Gradissa», en Creation and Re-creation: Experiments in Literary Form in Early Modern Spain. Studies in honor of Stephen Gilman, ed. R. E. Surtz y N. Weinerth, Newark, Delaware, Juan de la Cuesta, 1983, pp. 61-76.

11. Nombran distintas fuentes como Séneca, por ejemplo; Darino hace uso de Petrarca y los criados de Juvenal, Aristóteles o Serafino Aquilano. También se insertan máximas morales, sentencias filosóficas y avisos. Véase Regula Rohland de Langbehn, «Materiales sapienciales y emblemáticos en Penitencia de amor, de Pedro Manuel Giménez de Urrea», en Studia Hispanica Medievalia IV. Actas de las V Jornadas Internacionales de Literatura Española Medieval, Buenos Aires, Pontificia Universidad Católica Argentina, 1999, pp. 262-71. 
ha aprendido en los libros y no sólo con la práctica, como confiesa, sino a través de la lectura. ${ }^{12}$

Aunque vengo espantado de lo que e oýdo, no tengo del todo perdida la confiança, que porfiando no se alcançasse otra y otras cartas. Que yo sé qué cosa son mugeres, que aunque sean cuerdas y virtuosas, de contino les agrada la conversación y las alabanças, de donde naçen aviventezas y de las aviventezas los yerros. Esto alcanço yo por prática y por teórica (88).

En este sentido, Penitencia es una obra enteramente metaliteraria, puesto que dirige sus miras a la tradición precedente, la cual sigue, aunque no a pie juntillas, sino redefiniéndola, con el ánimo de hibridarla o incluso subvertirla con el sesgo de la ironía. ${ }^{13}$ Todas estas cuestiones acerca de la originalidad las trata Urrea de forma bastante críptica, desde luego, en ese prólogo que, si bien escueto, no tiene desperdicio alguno.

Aparte de ese término altamente significativo, arte de amores, la apreciación de que la obra se conforma "por cartas y por çenas» no deja de ser menos importante al respecto de su naturaleza y tiene mucho que ver con la estructura dramática. Se ha dicho innumerables veces que el diálogo, el modo dramático de la enunciación, procede de Celestina ${ }^{14}$ y que las cartas se asimilan desde la serie sentimental, especialmente de Cárcel de amor. Ahí radica, en efecto, uno de los hibridismos más palpables de la Penitencia. Ahora bien, no se entiende del todo por qué dice Urrea que la combinación de cartas y parlamentos dialogados «está ya muy usada en esta manera», si es el primero que las imbrica en España. Pero sí es posible que esté pensando en la Historia de duobus amantibus de Piccolomini, la primera narración que incluye el proceso epistolar y uno

12. En sus prólogos al Cancionero afirma Urrea: «La lectura es más agradable en prosa que en metro, porque se comprehenden mejor las razones, porque se allega más a nuestro hablar» (María Isabel Toro Pascua, El arte de la poesía: el Cancionero (Teoría e ideas sobre la poesía en los Siglos XV y XVI), Salamanca, SEMYR, 1999, pp. 102-103).

13. La ironía es uno de los pilares de muchas obras sentimentales, según opinión de la crítica más reciente, especialmente en el caso de Juan de Flores. Para la Penitencia de amor resulta fundamental, además de por otros extremos, Regula Rohland de Langbehn, «Penitencia de amor de Pedro Manuel Giménez de Urrea, ¿entre la Celestina y la novela sentimental?», Bulletin of Hispanic Studies, LXXIV 1 (1997), pp. 93-106.

14. Las huellas de la obra maestra ya las identificó María Rosa Lida de Malkiel, La originalidad artística de La Celestina, Buenos Aires, EUDEBA, 1970, $2^{a}$ ed. Véase asimismo, Ruth House Webber, "Pedro Manuel de Urrea y la Celestina» en La Celestina y su contorno social. Actas del I Congreso Internacional sobre la 'Celestina', ed. M. Criado de Val, Madrid, Hispam, 1977, pp. 359-366. Además, Regula Rohland de Langbehn «Algunos temas sociales de la 'celestinesca', considerados desde la perspectiva del género sentimental», en The Medieval Mind. Hispanic Studies in Honour of Alan Deyermond, ed. Ian Macpherson y Ralph Penny, Londres, Tamesis, 1997, pp. 363-80. 
de los referentes más claros de Urrea, tal como habremos de ver..$^{15}$ Sea como fuere, en relación con el arte de amores, ambos principios discursivos, "por cartas y por çenas", sirven de cauce a tres tipos distintos de actuaciones posibles. El proceso epistolar pone en contacto escrito a la pareja protagonista cuando ambos están ausentes; mediante el diálogo en presencia hablan los criados con el amo, o bien Renedo con Finoya y, por otra parte, en fin, se entrevistan o yacen Darino y Finoya. Por tanto, las conversaciones entre los criados, maestros en las tácticas eróticas, y su señor configuran el arte de amar propiamente dicho, mientras que las cartas y las obras amorosas constituyen la confirmación práctica de tales consejos. Esa estructura es la misma del Pamphilus, por ejemplo, puesto que primero Venus da una serie de castigos eróticos que más tarde lleva a cabo el amador. Más perfeccionada, incluso, se presenta en el Libro de buen amor, dado que la secuencia de enseñanza resulta doble. En efecto, la primera pieza erotodidáctica es el largo discurso de don Amor, tras el que interviene su esposa, dándole normas a don Melón, quien las lleva a cabo con doña Endrina.

De la combinación de cartas y diálogos, marcados cada uno de ellos con el epígrafe correspondiente, podemos diferenciar dos tipos básicos de segmentos dramáticos, ${ }^{16}$ algo así como los actos de la tradición terenciana, que no se señalan, sin embargo. Por su naturaleza distinta y específica de marco habrán de dejarse a un lado de este agrupamiento el prólogo, el argumento general y los segmentos I (1-2) ${ }^{17}$ y x (24-26), ${ }^{18}$ planteamiento y desenlace del proceso, respectivamente. El primer tipo de segmento contiene siempre un parlamento de Renedo y Angis con el amo, en donde se plantea la estrategia epistolar. A ello se une la propia carta de Darino con su correspondiente invención, ${ }^{19}$ la embajada de Renedo a Finoya con el fin de entregarle la misiva y, por último, la respuesta escrita de la dama. A este primer tipo corresponden los segmentos II (3-5), ${ }^{20}$ III (6-9), ${ }^{21}$ IV (10-

15. José Luis Canet Vallés lo adelanta en De la comedia humanística al teatro representable, Valencia, Universidad, 1993, pp. 49-53.

16. Estructuraciones parecidas proponen M. F. Aybar Jiménez, La ficción sentimental del siglo XVI, Madrid, Universidad Complutense de Madrid, 2001, pp. 265-71, dentro del amplio espacio que le dedica a la obra, pp. 249-333, y Françoise Vigier, «Fiction epistolaire et novela sentimental en Espagne aux xve et Xvie siècles», Mèlanges de la Casa de Velázquez, xx (1984), pp. 229-259, concretamente, p. 145.

17. Asigno a partir de aquí una numeración consecutiva a cada uno de los epígrafes que marcan las distintas intervenciones de los personajes. En este caso: [1] Darino. Finoya. [2] Darino solo.

18. [26] Nertano. Darino. Finoya. Renedo. Angis. [27] Razonamiento de Darino a Nertano. [28] Razonamiento de Finoya a Nertano, su padre.

19. De las invenciones y su valor se trata infra.

20. [3] Darino. Renedo. Angis. [4] Carta de Darino a Finoya. [5] Renedo. Finoya. Aquí no hay respuesta de Finoya porque rompe la misiva.

21. [6] Renedo. Darino. Angis. [7] Carta de Darino a Finoya. [8] Renedo. Finoya. [9] Respuesta de Finoya a Darino. 
$13)^{22}$ y VI (16-19). ${ }^{23}$ El segundo tipo engloba, por su parte, la estrategia o preparativos y, a continuación, el encuentro de los amantes. También son cuatro segmentos en este caso: V (14-15), ${ }^{24}$ VII (20-21), ${ }^{25}$ VIII $(22-23)^{26}$ y Ix (24-25). ${ }^{27}$ Esta paridad numérica nos hace ver en primer lugar el meditado equilibrio del diseño argumental. Asimismo, se observa cómo los segmentos V y VI, el eje simétrico del proceso amoroso y verdadero nudo de la acción, puesto que constituye el momento del cambio de actitud de Finoya, se intercambian su orden con respecto a las series anterior y posterior. Según este sencillo esquema, una primera sección de la trama (segmentos II, III y IV) correspondería sobre todo a las palabras y disquisiciones acerca del amor, mientras que la segunda (VII, VIII y IX) casaría con los hechos eróticos.

Semejante dicotomía entre palabras y obras resulta muy productiva para la caracterización del proceso amoroso y subraya el paso entre un bloque y otro de segmentos dramáticos. Y así se marca en el texto. Al preparar el primer encuentro, todavía diurno (Iv), Angis le adelanta a Darino: «Pues que tú vayas, señor, hablar con Finoya, acabado es el fin desto. No quedará en tan poco, yo te digo de cierto, que pues que aora viene a palabras que después verná a obras, que ya dizen que 'quien osa dezir osará hazer"» (94), algo que luego le confirma la propia Finoya: "Tus buenas palabras no an de hazer malas mis obras» (96). Igualmente, Renedo, el otro criado, viene a establecer la misma evolución antes de la acometida de Darino en casa de la dama: "Pues ya se açerca la ora no aya muchas palabras, que en esta sazón todo a de ser obras» (110). De todas formas, en el Argumento inicial ya se adelantaba que «Fue tal la diligencia y astucia de sus criados, que alcançó Darino al principio reçebir cartas de Finoya y al cabo gozar de su persona» (72).

Otra consecuencia que se desprende de la estructura comentada es la reiteración de las situaciones dramáticas y, por tanto, de los esquemas de intervención, de forma que se cuentan cuatro segmentos de cartas $y$ otros tantos de encuentros entre los enamorados. Esta compensación viene a subrayar la necesidad del proceso misivo como medio más eficaz del arte de amar, en tanto que propicia los acercamientos cada vez más íntimos de la pareja. He aquí el principal ingrediente para la recurrencia o mecanicismo de las acciones que implican esa connotación determinista antes mencionada, la cual no sólo parte del condicionamiento naturalista del texto, sino de su conformación, tal como se diseña en el prólogo. Asi-

22. [10] Renedo. Darino. Angis. [11] Carta de Darino a Finoya. [12] Renedo. Finoya. [13] Respuesta de Finoya a Darino.

23. [16] Darino. Renedo. Angis. [17] Carta de Darino a Finoya. [18] Renedo. Finoya. [19] Respuesta de Finoya a Darino.

24. [14] Renedo. Darino. Angis. [15] Darino. Finoya.

25. [20] Renedo. Darino. Angis. [21] Darino. Finoya.

26. [22] Darino. Renedo. Angis. [23] Darino. Finoya.

27. [24] Darino. Renedo. Angis. [25] Darino. Finoya. 
mismo, se refuerza la idea básica del arte de amores, que consiste en la aplicación de tácticas y mañas, de todas las que sean necesarias y con una actitud siempre diligente. Como dice Renedo a su señor en el segmento II: «hallarás en mí diligencia y fidelidad; y, sobre todo, lo que es más necessario, que es una poca desdicha y ventura en esto más que en otro, que algunas vezes viene por la diligencia la suerte, quando se sabe procurar» (76). El otro componente indispensable para llegar a medrar es la fortuna, que según Renedo siempre acude al lado de la diligencia. Él piensa que Darino está tocado por la buena ventura, entre otras causas por la calidad de su linaje. ${ }^{28}$ Le dice: "No desesperes; ten confiança, que tu ventura y mi diligencia bien podrán bastar para la flaqueza de una muger» (78). A pesar de todo, Darino coincide con Renedo en que lo que nunca ha de faltar es la buena disposición y el trabajo: "Mas ase de mirar que haga hombre lo que debe, y piérdasse por la ventura y no por la negligencia» (76).

Tan necesaria es la aplicación del arte de amar que el primer encuentro fortuito entre Darino y Finoya no lleva a ningún acuerdo. La trama de Penitencia de amor comienza in media res, como Cárcel de amor o la Celestina, con el parlamento del caballero a la dama, que éste se encuentra a la ventana de su castillo, tal como se anuncia en el Argumento previo (77). Un argumento que sirve para que los lectores se enteren de algunos aspectos escamoteados más tarde. Darino, después incluso de ofrecer su propia vida a la dama y de hacer alusiones a un posible suicidio, no consigue más que el desplante de Finoya, la cual tiene muy claro lo falaz de los requiebros cortesanos. Ante esa negativa, Darino enuncia un soliloquio (75) que constituye una oración a Dios, donde le pide perdón por su loco amor, pero donde también insiste en que ese apetito es inherente a su naturaleza. En definitiva, esas palabras de desesperanza muestran la imposibilidad de la unión erótica, sin que medie un arte de amar articulado por unos terceros. Esta primera escena de desencuentro procede de toda una larga tradición que comienza con el Pamphilus, pasa por Piccolomini y llega a la Celestina. Más original parece el Soliloquio de Darino, un modelo retórico que no se encuentra en la Tragicomedia y que tal vez provenga de Piccolomini.

En la siguiente escena Darino dice encontrarse en una cárcel de desesperación, una idea esta de la prisión que se repite en varios lugares y que quizá sea un leve recuerdo de la cárcel alegórica que mantiene preso a Leriano y que da nombre a la Cárcel de amor. La situación resulta idéntica a la del acto i de la Celestina, aunque la naturaleza de los personajes no sea la misma. Darino es un amador tan lascivo como Calisto o incluso más osado, si cabe. Pero los criados Renedo y Angis poco tienen que ver con Sempronio y Pármeno. Ambos son mayores que su señor y más experi-

28. Renedo le dice: «eres más bivo por el linaje, que siempre la mayor sangre haze más bivo el ingenio, aunque algunos de baxa manera en cosas de bellaquería pueden ser más despiertos» (77). 
mentados, por eso son los maestros perfectos para mostrarle el arte de amores. Darino piensa que Renedo es el intermediario más adecuado con Finoya por estar libre de pasión («pues que conozco que tú bastas como libre y ajeno de passión para pensar la forma que se a de levar en esta tan grande enpresa», 79), lo cual lo equipararía al auctor de Cárcel de amor. Además, los dos criados le son fieles y comparten de modo absoluto la misma mentalidad señorial. Por eso no usan nunca los apartes, como ocurre en Celestina. ${ }^{29}$ Téngase en cuenta además que ambos criados, sobre todo Renedo, asumen también la función de la alcahueta, que en la obra de Urrea no aparece por ningún sitio. ${ }^{30}$ Sí existen unas parcas alusiones a un contacto con las criadas de Finoya, que tal vez recuerde la relación de Pármeno y Sempronio con las mochachas de Celestina. Sea como fuere, estos criados mantienen el mayor parecido con el sesudo y fiel Sosias de la Historia de duobus amantibus. ${ }^{31}$

\section{"Cada carta tuya es un combate...»}

Desde el principio de su intervención, los mediadores proponen la táctica de enviar cartas como sistema más adecuado en la conquista amorosa. Angis le pide a Darino que cuente su desafortunado encuentro $(78)^{32} \mathrm{y}$ le da muestras de su solicitud: «Lo que yo sobre esto digo es que me pareçe que digas quién es aquélla que tú tienes por señora, y que le escribas una carta, que uno de nosotros se pondrá en qualquier peligro por hazer tu mandado, procurando todo el descanso que somos obligados» (77-78). El encargado de trasladar los escritos a Finoya va a ser siempre Renedo, para evitar que la dama sospeche que el caso está en boca de muchos. Renedo coincide totalmente con la opinión de su compañero en que las cartas constituyen la fórmula más adecuada para sospesar la situación: «Mi pareçer es que me des una carta y tentemos qué tan hondo está este vado» (79). Ante la negativa de Finoya a contestar la primera epístola de Darino, en el segmento III, Renedo insiste en la necesidad de hacerle llegar una segunda: "Escrive otra carta que, aunque dizen que es neçio el que buelve al peligro donde escapó, yo bolveré con entera voluntad. Escrive por entero tu passión» (83). Darino no las tiene todas consigo, no obstante, y piensa que de nuevo no va a obtener respuesta. Y así se lo comunica a la amada: «My perdición es llegada, pues que me es dañoso lo que más me conviene; pues que mi carta no a de ser leýda, en valde va mi trabajo»

29. En definitiva, Renedo y Angis se parecerían más a Tristán y Sosias que a Pármeno y Sempronio.

30. Váyase a mi artículo "Los casos de amor...».

31. Bien es verdad que éste con un exceso de celo que impide la consecución amatoria en ocasiones.

32. Darino añade datos sobre lo que se cuenta en el Argumento. 
(85). En esto, sin embargo, se equivoca de plano, porque Finoya le ofrece una respuesta, indicándole, eso sí, que será la única y última, hecho que tampoco ocurrirá, al remitirle otras dos: «Ésta quiero que sea la primera y postrera carta que de mí as de tener; y ésta, en siendo leýda, rasga, porque no va para más de que sepas por mí que tu loca empresa no puede tener descansado fin» (87).

Fundamental, en fin, en el proceso de cartas viene a ser el segmento Iv, que supone la transición hacia los encuentros en presencia. La primera reacción de Darino ante la carta de Finoya recuerda el lloriqueo desmedido de Calisto sobre el cordón de Melibea:

Yo te beso, carta, que traes razones pensadas del gentil entendimiento de aquélla que no tiene comparación. ¡Oh palabras escriptas por aquella mano blanca y delicada! ¡Oh papel guardado en aquella arquilla donde tiene aquella dama el espejo y atavíos, sin los quales ella puede pareçer donde quiera y ninguna delante della! ¡Oh cómo huele a los suaves perfumes de quien la embía!... (88)

Renedo, por su parte, ha puesto toda la carne en el asador en su embajada epistolar y prácticamente le ha arrancado la misiva de respuesta, pero está muy seguro de que esta primera carta de la dama no ha de ser la postrera. Dice al respecto: «Aunque vengo espantado de lo que e oýdo, no tengo del todo perdida la confiança, que porfiando no se alcançasse otra y otras cartas» (88). Y Angis confirma la misma presuposición, cuando le dice a Darino: "no te tengas en poco, que yo por çierto tengo que as de recebir cartas de tanto amor como ésta de dolor» (88). Las cartas deben ir acompañadas, en cualquier caso, de regalos y otros presentes, tal como sugiere Renedo: «Pero yo soy de pareçer que curemos nosotros tanto de apretar a Finoya con cartas como con otras gentilezas, porque los requiebros también piensan ellas que los hazemos por ser loados, y que si juegas a cañas, que es porque digan que eres buen cavallero. No por las cartas a de parar esto, mas lo uno y otro juntamente...» (89). A pesar de la insistencia de los criados, Darino todavía no está conforme con los efectos del procedimiento y estima que las cartas no surtirán el debido efecto. Sin embargo, Angis es tajante ante esta reticencia y conmina al amo en términos vehementes:

No solamente digo que no se deve escusar el escrevir otra carta, mas digo que no se deve tardar. Ya començando a escribir, Finoya no parará. Poco a poco yrá perdiendo el fingido enojo que tiene y quiçá muy presto, según se rigen algunas por estremos. Lieve otra carta Renedo, que en esta segunda respuesta suya conoçeremos las mudanças suyas, que con las libiandades se acompañan. 
Por muy alcançado tengo yo tu deseo; tanto es lo que yo creo como lo que tú dudas. Cata que las mugeres son más mudables que el día: si ésta al principio, como la mañana, haze fuerte, a la postre se suele mudar el día. (89-90)

En efecto, Renedo presupone que en la segunda respuesta de Finoya se atisbarán ya cambios en su opinión, algo que, desde luego, no tarda en ocurrir. Y es que como le dice al amo el criado, cuando le pide la carta para Finoya: "Cada carta tuya es un combate». La entrevista consecuente resulta fundamental en el progreso amoroso, puesto que se concierta la primera cita entre Darino y Finoya, un encuentro que todavía ocurre de día y que la dama certifica en la carta que entrega a Renedo. Por eso el segmento dramático $\mathrm{v}$ se centra en la conversación de ambos, un enfrentamiento dialéctico en el que Finoya mantiene aun muchos temores y donde se muestra bastante esquiva. De ahí que en el segmento vi Angis continúe viendo la necesidad de insistir con las cartas de rigor: «Con cartas, es mi pareçer, se deve porfiar, porque es más gala que el interesse» (98). Una propuesta a la que se une, por supuesto, Renedo: «De dexar lo enprendido no se deve hablar. Gran poquedad sería; pues para pasar adelante, las cartas es el mejor remedio» (98). Este segmento dramático, al igual que el anterior, resulta crucial en el desarrollo de la trama, dado que supone el inicio inevitable del vencimiento amoroso de Finoya. Las cartas de Darino y su conversación terminan por ablandar el corazón de la dama, tal como han ido vaticinando los servidores del enamorado. La carta tercera de Finoya no deja lugar a dudas, al sostener que la conversación le ha agradado finalmente. Además supone el visto bueno a la cita que le ha solicitado Renedo para la media noche. Pero aparte de los términos explícitos que se deducen de las conversaciones y las cartas, existe otro importante indicio del cambio interior que se va produciendo en Finoya. Las invenciones o letras de justadores que acompañan todas las epístolas de Penitencia de amor entrañan un significado simbólico. Si en la carta primera Finoya adjuntaba una letra sobre una vihuela sin cuerdas, ${ }^{33}$ imagen clara de la imposibilidad del amor, las otras dos invenciones van progresando hacia lo positivo. La segunda letra hace referencia a unos árboles todavía pequeños, pero que, en tanto que árboles, han arraigado, desde luego. ${ }^{34}$ Ahora la tercera invención se centra en el simbolismo del pavo real, una imagen ambivalente por la belleza de la cola del animal, en contraste con la fealdad de los pies. ${ }^{35}$ En esa tesitura se encuentra la amada.

33. «No tienes más esperança / de alcançar lo que concuerdas, / que esa de tañer syn cuerdas» (87).

34. «Embía Finoya a Darino unos árboles pequeños y dezía la letra: / Estos tyenen más que tyenes, / que darán fruto con flores, / lo que no ay en tus amores» (93).

35. "Embia Finoya a Darino un pavo y dezía la letra: / Su ermosura es tu pensar, / y sus pies son tu esperança, / y su voz tu confyança» (104-105). 
En realidad, el proceso de cartas de amores constituye en Penitencia un modelo de pequeño ars dictaminis, donde se codifica una casuística de propuestas, así como la explicación de su intención en cada momento. También la adecuación a los acontecimientos, de forma que no sólo aparecen los ejemplos de cartas, sino también la función de cada una y la reacción que surte en la pareja. En este proceso epistolar radica, en definitiva, el verdadero arte de amores. En un sentido tal, el núcleo epistolar de Penitencia de amor podría ponerse en relación con obras como la Rota veneris ${ }^{36}$ o con el pliego Cartas y coplas para requerir nuevos amores. ${ }^{37}$ Todo ello, a pesar de que la construcción estructural del proceso con un intermediario o embajador tan activo, pero tan respetuoso como Renedo, se parece sobre todo al de Cárcel de amor, obra que presenta, quizá, el conjunto de cartas más elaborado y modélico ${ }^{38}$ de toda la serie sentimental. ${ }^{39}$ Lo que sí podría ser un elemento asumido desde la tradición y, por tanto, mecánico es el número de misivas enviadas. Ha de recordarse que Darino remite a Finoya cuatro cartas y que ésta le responde con tres. Pues bien, Arnalte también escribe exactamente cuatro misivas y Leriano hace lo propio con Laureola. Esto, desde luego, no puede ser una casualidad, máxime cuando observamos que en la Historia de duobus amantibus, el núcleo de las cartas iniciales está conformado asimismo por cuatro escritos. Así pues, San Pedro habría tenido en cuenta quizá el modelo de Piccolomini y Urrea partiera tal vez de ambos. Lo que sí cambia, no obstante, es la proporción de las respuestas en cada uno de los casos. Finoya, con tres respuestas, oscila entre Lucenda, que sólo escribe una, y Laureola, que responde con evasivas a las cuatro de Leriano, las mismas respuestas de Lucrecia, a pesar de que esta rompe la primera de las suyas.

\section{"Aora viene a palabras, que después verná a obras...»}

En correspondencia con el proceso epistolar la evolución de los encuentros amorosos, la otra sección del conjunto, obedece a una gradación bien

36. Ahora editada y traducida en Antonio Cortijo Ocaña, Boncompagno da Signa. El Tratado del Amor carnal o Rueda de Venus. Motivos literarios en la transición sentimental y celestinesca, (ss. XIIIXV), Pamplona, EUNSA, 2002.

37. Véase Pedro Cátedra, Tratados de amor en el entorno de Celestina (siglos XV-XVI), Madrid, Sociedad Estatal España Nuevo Milenio, 2001, pp. 249-259. Ha de tenerse en cuenta que en un volumen facticio de la Biblioteca Nacional de Francia Penitencia de amor aparece encuadernada junto con las tres obras de Diego de San Pedro, las Cartas y coplas para requerir nuevos amores y una colección de romances.

38. Véase Sol Miguel-Prendes, «Las cartas de la Cárcel de amor», Hispanófila, 102 (1991), pp. $1-22$.

39. Para el estudio de la epístola sentimental resulta imprescindible Françoise Vigier, «Fiction epistolaire et novela sentimental en Espagne aux xve et XVIe siècles». Asimismo, Antonio y Adelaida Cortijo Ocaña, «Las cartas de amores: ¿otro género perdido de la literatura hispánica medieval?», Dicenda, 19 (1999), pp. 34-58. 
articulada, aunque también con modelos evidentes. Como ya hemos visto, la primera conversación entre Darino y Finoya ocurre de día y sirve fundamentalmente para dar pie al segundo encuentro, ya de noche. El cambio de actitud de la amada ha sido espectacular desde sus prevenciones iniciales, tanto que el propio Angis se escama de que pudiera tratarse de alguna burla o emboscada:

De todas las cosas es bueno ni mucho osar ni mucho esperar, syno un medio, que el tenor por eso es çimiento de la música, porque está en medio della. Esto de Finoya no tiene medio; ayer nos amenazó y oy nos convida. Mas quando pienso que algunas son que usan de su naturaleza flaca y débil, después que tú hablaste puede estar muy contenta de ti, señor. (99)

Urrea, desde luego, ha eliminado el ingrediente diabólico de la Celestina para la philocaptio de la amada, ausencia que supondría en principio un abandono de la verosimilitud argumental. Sin embargo, en otros textos anteriores a Rojas el cambio experimentado por la amada desde el rechazo a la aceptación se logra exclusivamente por mediación de las tercerías. Así ocurre en el Pamphilus de amore y, por supuesto, en la historia de don Melón y doña Endrina. También ocurre en un texto en la órbita celestinesca, un Tratado de amores, que, aunque nos ha llegado fragmentario, ${ }^{40}$ parece dar a entender un rendimiento súbito de la dama después de la tercera misiva del amador, produciéndose quizá el encuentro amoroso en el resto del proceso, que lamentablemente desconocemos.

Ante unas expectativas bastante halagüeñas, Darino se viste para la ocasión con colores altamente simbólicos de esperanza y alegría, el verde y el grana. No es para menos, en efecto, porque Finoya coquetea desde su ventana con el enamorado y deja caer un abanico que Darino recoge y trata con fruición. Una imagen simbólica de la entrega amorosa que se producirá en breve. En este momento Darino solicita la entrada en la cámara de la dama, último peldaño en el proceso erótico, y ella accede a otorgarle el permiso para la medianoche siguiente. ${ }^{41}$ Los preparativos para la entrada en la casa de la amada requieren ciertos cuidados, como por ejemplo, que los criados hayan trabado amistad con sus criadas, con el fin de desviar la atención. Por otro lado, las pretensiones exclusivamente eróticas de Darino se ponen al descubierto y no piensa en otra cosa que en recaudar. Dice: "Ya la sangre me vulle por verme en lo que dizes» (110). La vehemencia del amador resulta más que evidente y actúa conforme a esa dosis de violencia que aconseja la normativa ovidiana. La

40. Véase la edición de Consuelo Gonzalo García, en Cátedra, Tratados..., pp. 83-92. Lo descubrió Carmen Parrilla, «El Tratado de amores: nuevo relato sentimental del siglo XV», El Crotalón: Anuario de Filología Española, 2 (1986), pp. 473-86

41. Siguiendo, en efecto, el esquema de la Celestina. 
escena erótica se representa de modo bastante explícito, con una serie de lamentos entrecortados por parte de Finoya, que recuerdan los encuentros respectivos del Pamphilus ${ }^{42}$ o la Historia de duobus amantibus, ${ }^{43}$ los dos textos tal vez más explícitos al respecto. Pero la clave del asunto se concentra en el argumento esgrimido por Darino a partir de aquí. Según su visión absolutamente naturalista, ${ }^{44}$ esa reticencia inicial de la amada forzada se disolverá en no más de tres días y se convertirá en placeres $y$ risas. Por ese motivo es necesario un segundo encuentro erótico, para que se represente un ayuntamiento carnal finalmente consentido y con su beneplácito. Los preparativos y pláticas del segmento IX insisten en la dimensión naturalista del loco amor. Darino se ha convertido en un bocazas que brinda detalles sobre la belleza de las intimidades de Finoya y los criados debaten sobre la cuestión de la filosofía natural. Pero en esa conversación previa se insertan otros asuntos claves, como la alusión a la tristeza de Nertano, padre de la dama. Esto lleva a intuir que algo barrunta sobre la traición de su hija. Además aparecen esas "pullas honestas» de Angis con Lantoyo que tanto han desconcertado a la crítica. ${ }^{45}$ Suponen un contrapunto burlesco precisamente en el punto culminante de la acción, marcado entre otras cosas por la alusión fatal al padre de Finoya. Las pullas constituyen un recuerdo de la tradición eclógica del teatro representable, que el propio Urrea desarrolla en otra parte de su producción. ${ }^{46}$ Desde un punto de vista del proceso dramático esa pieza abunda en el trato y conocimiento de los criados con los de casa de Finoya y sirve para avisar a la dama de que Darino ha llegado con los suyos. La segunda noche de amor nos presenta, en fin, a una Finoya más desinhibida, que trata a Darino con términos de mayor complicidad. Predisposición que concuerda con esa especie de carpe diem que Darino le propone para reconfortarla: "Si tu madre por ser vieja va rezando con sus cuentas, tú por ser moça as de yr tomando deleytes, que ella ya a posado ese mesón. No cumple santidades, que todos somos umanos. Yo no debría hablarte desto syno de otros plazeres; mas porque te veo algo desconsolada quiero dezirte cómo yerras en tener fatiga de lo que es plazer» (122). Pero el final está a

42. Ed. cit., pp. 167-169.

43. Enea Silvio Piccolomini, Estoria muy verdadera de dos amantes, ed. Ines Ravasini, Roma, Bagatto Libri, 2003, p. 362.

44. Ese componente naturalista lo he estudiado en mi artículo «Penitencia de amor..., pp. 500-505.

45. Podrían tener relación con los disparates de la Triste deleytación. Para este asunto, véase Vicenta Blay Manzanera: «El humor en Triste deleytaçión: sobre unas originales coplas de disparates", Revista de Literatura Medieval, 6 (1994), pp. 45-78

46. Para el teatro de Urrea la mejor aproximación la constituye Aurora Egido, «Aproximación a las Églogas de Pedro Manuel de Urrea», en I Curso sobre Lengua y Literatura en Aragón (Edad Media), coord. Tomás Buesa y Aurora Egido, Zaragoza, Institución Fernando el Católico, 1991, pp. 217-55. Los textos han sido editados en Eugenio Asensio, Églogas dramáticas y poesías desconocidas, Madrid, Joyas Bibliográficas, 1950. 
la vuelta de la esquina y el sonido de los pasos de Nertano acaba con la intimidad de los enamorados.

Las causalidades que concatenan el proceso amoroso resultan más que evidentes. Al primer encuentro diurno le sigue una cita por la noche, presagio de la entrada en la alcoba que tiene lugar por dos veces. La primera supone casi un acto forzado, como el de Pamphilus con Galatea o don Melón con Endrina. Pero esa primera intentona deja lugar a una segunda en que el placer de la dama va cediendo a su temor inicial. Si hubiera que comparar con algún modelo para interpretar el transcurso final del caso de amores, habría que decidirse sin duda por la Tragicomedia. En Celestina el desenlace fatal, aunque han tenido lugar otros muchos encuentros eróticos, ocurre en el segundo de los representados, al igual que en la $\mathrm{Pe}$ nitencia. Y téngase en cuenta que esta es la diferencia fundamental desde la Comedia, donde el final trágico resultaba inminente, produciéndose la primera noche de amor. Entre el capítulo XIV y el XIX se introduce entonces el conocido como Tratado de Centurio, que abunda sobre la perspectiva de los criados y la venganza que planean las muchachas por la muerte de sus compinches. Pues bien, todo el asunto de las relaciones entre los criados de una y otra parte y esas pullas honestas que se intercambian podría constituir el recuerdo, muy difuso de todas formas, de esa cuña novedosa en la Tragicomedia, si bien con una finalidad completamente distinta.

\section{El hibridismo final}

A pesar de ese seguimiento general de la Tragicomedia, Ximénez de Urrea se separa de la Celestina en el desenlace del caso de amor (segmento $\mathrm{x}$ ), uno de los momentos más desconcertantes de la obra. Como corresponde al ejercicio del loco amor Calisto y Melibea habían muerto para pagar su pecado. Calisto de un modo accidental y casi ridículo y Melibea con la grandeza heroica que corresponde a los suicidas. En este final desastrado Fernando de Rojas se insertaba en la tradición sentimental que sanciona castigos de ese tipo cuando existe ayuntamiento carnal, ${ }^{47}$ frente al final feliz que caracteriza a la comedia humanística. La autoinmolación de Melibea podría recordar el acto de Mirabella, cuando se arroja a los leones. Ahora bien, la muerte antiheroica de Calisto al caer de la escala incorpora una dimensión debida al fatum adverso que resulta desconocida en la tradición anterior. Tales amadores se suicidan, como Ardanlier, Grisel, no sabemos si Leriano; se dejan morir por consunción o se retiran a la soledad de los campos, como Grimalte, Pánfilo o Arnalte.

47. La más cabal gramática amorosa de la ficción sentimental la ofrece Regula Rohland de Langbehn, La unidad genérica de la novela sentimental española de los siglos XV y XVI, Londres, Queen Mary and Westfield College, 1999. 
Sin embargo, en Celestina existe un cambio importantísimo con respecto a los padres vengadores ${ }^{48}$ de la honra femenina como el padre de Mirabella o el de Laureola, y en su momento el rey Croes en Siervo libre de amor. Bien es verdad que Pleberio no es un rey que tenga que salvaguardar los principios públicos del reino. Únicamente funciona como padre de la amada, en el ámbito privado. En este sentido se parecería en su función a las madres respectivas de Mirabella y Laureola y sobre todo, por el llanto tras la muerte de su hija, a la madre de Leriano. ${ }^{49} \mathrm{Tal}$ como ya mencioné, la amada suicida que primero se nos viene a la cabeza cuando reparamos en Melibea es Mirabella, princesa de Escocia, cuyo padre implacable se encarga de castigar por su unión carnal con Grisel, que también se autoinmola. Ya Barbara Matulka se dio cuenta de que los últimos Razonamientos de la Penitencia, cuando Darino y Finoya se autoinculpan por su mayor responsabilidad en los yerros de amor, se basan en lo que ella denominó combate de generosidad entre Grisel y Mirabella..$^{50}$ Nertano desde luego, se parece más a los padres de la ficción sentimental, ejecutores de los castigos, que a Pleberio, puesto que toma cartas en el asunto de la honra. Pero, sin embargo, no aplica el criterio tal como correspondería a un amor que ha sido consumado. En consecuencia, no manda matar a los responsables, sino que se limita a encerrarlos a cada uno de ellos y sus criados en una torre para que cumplan la penitencia. Afirma:

No he querido daros muerte a vos, hija, porque el coraçón no me lo a çufrido; y a vos, Darino, no he querido mataros porque penéys más. La fama que se pondrá a de ser que Finoya, mi hija, es muerta y assí le haremos las onras; y de Darino se dirá que se a ydo al cabo del mundo. Unos creerán que por veer tierras, otros que de desesperado se a ydo por la muerte de mi hija, que ya sabían que la quería. Vamos, que ello será tan secreto quanto traydor (123).

Esta irresolución por parte de Nertano resulta ser, por tanto, el acto que más profundamente contradice el principio de automatismo que rige la obra, frente a la muerte consabida en casos de amor de esta suerte. Por eso ha de entenderse como un ejemplo de elemento irónico. Y el caso es que el propio Darino, ya sabemos que plenamente al tanto de las convenciones sentimentales, le recrimina que no haya aplicado la pena máxima,

48. Para la función de padres y madres en la serie sentimental, véase Patricia E. Grieve, "Mothers and Daughters in Fifteenth-Century Spanish Sentimental Romances: Implications for Celestina», Bulletin of Hispanic Studies, 67 (1990), pp. 4-13.

49. Luis Miguel Vicente, «El lamento de Pleberio: Contraste y parecido con dos lamentos en 'Cárcel de amor'», Celestinesca, XII (1988), pp. 35-43.

50. Barbara Matulka, The novels of Juan de Flores and their European diffusion, New York, Institute of French Studies, 1931, pp. 181-183. 
tal como le correspondería a un modélico padre justiciero. Al menos a él, verdadero culpable, debía de haberlo matado:

\section{Razonamiento de Darino a Nertano.}

Perdona mi osadía, que con la desesperación no puedo estar sin dezillo. No te as regido en esto como cavallero, porque avías de matar a mí, y con la misma fama que he ydo a ver mundo se encubriera. Y pues yo fuera muerto no cumpliera matar a Finoya, que no se supiera nada. ¿Cómo as podido çufrir el desamor que a mí me tienes, dándome tan poca penitencia en pago de lo que yo he hecho? Y a Finoya, el amor de padre, ¿cómo la puede encarçelar? De la enemistad mía y del amor de ella as usado muy mal. ¿En qué batalla me as vençido que me tienes encarçelado? Qué tan libre me as dexado, según lo que he acometido, y qué tan atado me tienes, según lo que merezco. Acaba ya de matar a mí y de soltar a Finoya; yo pagaré por los dos. No uses de justicia de yglesia, que es misericordia, que no mata a nadi. Tu mucho coraçón no çufra que des ygual pena a tu hija y a tu enemigo. Yo he de ser el condenado y ella la asuelta. Mas según lo que en ti veo, no mudarás la miserable sentencia y mal pensada presión, que tu dudosa condiçión a ordenado (123-124).

Desde luego, Nertano no actúa conforme a las leyes sentimentales. Ahora bien, hay que tener en cuenta que no se trata de un rey, ni Finoya de una princesa. Esta condición de plebeyo le otorga una libertad, un comportamiento dentro de los márgenes de la privacidad, que no son posibles en los casos de Mirabella o Laureola. Por eso Nertano se queda más o menos en la mitad entre los reyes vengadores y el comprensivo Pleberio. Parece que Urrea ha optado por una fórmula de compromiso, que incorpora el castigo pero no lo lleva hasta sus últimas consecuencias.

Por más que el castigo parezca insuficiente según los parámetros de la norma sentimental, el caso es que la penitencia existe y se cumple. Ello viene a confirmar una norma generalizada en las artes de amores, las cuales llevan aparejada a su vez la correspondiente reprobación del amor, que aquí se manifiesta desde el título. Sin ir más lejos, repárese en Ovidio o Capellanus, el propio Libro de buen amor y, desde luego, la Historia de duobus amantibus o la Celestina. Posiblemente Ximénez de Urrea tenga en cuenta a casi todos esos modelos, pero a la luz del final anómalo o la inserción de las pullas humorísticas y, sobre todo, del distanciamiento con que se manifiesta en el prólogo, habría que preguntarse si el mecanicismo del argumento de la obra y su estructura matemática no son más que una mirada irónica sobre los presupuestos de un género demasiado encorse- 
tado en sus propias convenciones. Así pues, a base de taracear y mezclar de aquí y de allá, la Penitencia de amor resulta ser un producto híbrido, a veces contradictorio, pero digno representante del final de una etapa en la concepción amorosa de raigambre cortés, que habrá de ser sustituida en unos tres lustros por la renovación del modelo petrarquista. 


\section{Bibliografía}

Asensio, Eugenio (1950), Églogas dramáticas y poesías desconocidas, Madrid, Joyas Bibliográficas.

Aybar Jiménez, M. F. (2001), La ficción sentimental del siglo XVI, Madrid, Universidad Complutense de Madrid.

Blay Manzanera, Vicenta (1994), "El humor en Triste deleytaçión: sobre unas originales coplas de disparates", Revista de Literatura Medieval, 6, pp. 45-78.

Blay Manzanera, Vicenta (1994), «Metaliteratura y reflexividad en la ficción sentimental: La primera generación", Anuario Medieval, vI, pp. 3974.

CAnet Vallés, José Luis (1993), De la comedia humanística al teatro representable, Valencia, Universidad.

CANET, José Luis (1992), «El proceso de enamoramiento como elemento estructurante en la ficción sentimental», en Historias y ficciones: coloquio sobre la literatura del siglo XV, ed. R. Beltrán, J. L. Canet y J. L. Sirera, Valencia, Universitat de Valencia, Departament de Filologia Espanyola, 1992, pp. 227- 39.

CáTEDRA, Pedro (2001), Tratados de amor en el entorno de Celestina (siglos XVXVI), Madrid, Sociedad Estatal España Nuevo Milenio.

Cortijo Ocaña, Antonio (2002), Boncompagno da Signa. El Tratado del Amor carnal o Rueda de Venus. Motivos literarios en la transición sentimental y celestinesca, (ss. XIII-XV), Pamplona, EUNSA.

Cortijo Ocaña, Antonio y Adelaida (1999), «Las cartas de amores: ¿otro género perdido de la literatura hispánica medieval?», Dicenda, 19, pp. 34-58.

EGIDO, Aurora (1991), "Aproximación a las Églogas de Pedro Manuel de Urrea», en I Curso sobre Lengua y Literatura en Aragón (Edad Media), coord. Tomás Buesa y Aurora Egido, Zaragoza, Institución Fernando el Católico, pp. 217-55.

Foulché Delbosc, R. (1902), «La Penitencia de amor de Pedro Manuel de Urrea», Revue Hispanique, 9, pp. 200-215.

GerLI, E. Michael (1989), "Metafiction in Spanish Sentimental Romances», en The Age of Catholic Monarchs; 1474-1516: Literary Studies in memory of Keith Whinnom, Liverpool University Press, pp. 57-63.

Gómez, Jesús (1990), "Las «Artes de amores», Celestina, y el género literario de la Penitencia de Amor de Urrea", Celestinesca, 14.1, pp. 3-16

Grieve, Patricia E. (1990) «Mothers and Daughters in Fifteenth-Century Spanish Sentimental Romances: Implications for Celestina», Bulletin of Hispanic Studies, 67, pp. 4-13.

Lida de Malkiel, María Rosa (1970), La originalidad artística de La Celestina, Buenos Aires, EUDEBA, 2-ed. 
MatulKa, Barbara (1931), The novels of Juan de Flores and their European diffusion, New York, Institute of French Studies.

Menéndez Pelayo, M. (1943), Orígenes de la novela, iII, ed. Enrique Sánchez Reyes, Edición Nacional de las Obras Completas de Menéndez Pelayo, Madrid, CSIC.

Miguel-Prendes, Sol (1991), "Las cartas de la Cárcel de amor», Hispanófila, 102, pp. 1-22.

NúÑ̃Ez Rivera, Valentín (2006), "Penitencia de amor en la tradición sentimental (Porque todo lo que es ha sido)", Bulletin of Spanish Studies, LXXXII., 4, pp. 481-505.

Núñez Rivera, Valentín (en prensa), «Los casos de amor desde Juan de Flores hasta Celestina. Entre terceros y mezcladores» en Homenaje a Klaus Wagner, ed. Piedad Bolaños et al., Sevilla, Universidad.

PAMPHILUs de amore (1991), ed. L. Rubio y T. González Rolán, Barcelona, Bosch, pp. 95-103.

Parrilla, Carmen (1986), "El Tratado de amores: nuevo relato sentimental del siglo XV», El Crotalón: Anuario de Filología Española, 2, pp. 473-86.

Piccolomini, Eneas Silvio (2003), Estoria muy verdadera de dos amantes, ed. Ines Ravasini, Roma, Bagatto Libri.

Rohland DE LANGBeHn, Regula (1997), "Algunos temas sociales de la 'celestinesca', considerados desde la perspectiva del género sentimental», en The Medieval Mind. Hispanic Studies in Honour of Alan Deyermond, ed. Ian Macpherson y Ralph Penny, Londres, Tamesis, pp. 363-80.

Rohland de Langbehn, Regula (1997), "Penitencia de amor de Pedro Manuel Giménez de Urrea, ¿entre la Celestina y la novela sentimental?», Bulletin of Hispanic Studies, LXXIV, 1, pp. 93-106.

Rohland De LangbeHn, Regula (1999), "Materiales sapienciales y emblemáticos en Penitencia de amor, de Pedro Manuel Giménez de Urrea», en Studia Hispanica Medievalia IV. Actas de las V Jornadas Internacionales de Literatura Española Medieval, Buenos Aires, Pontificia Universidad Católica Argentina, pp. 262-71.

ROHLAND De LANGBEHn, Regula (1999), La unidad genérica de la novela sentimental española de los siglos XV y XVI, Londres, Queen Mary and Westfield College.

Toro Pascua, María Isabel (1999), El arte de la poesía: el Cancionero (Teoría e ideas sobre la poesía en los Siglos XV y XVI), Salamanca, SEMYR.

Vicente, Luis Miguel (1988), "El lamento de Pleberio: Contraste y parecido con dos lamentos en 'Cárcel de amor'», Celestinesca, XII, pp. 35-43.

VigIER, Françoise (1984), "Fiction epistolaire et novela sentimental en Espagne aux Xve et XVIe siècles», Mèlanges de la Casa de Velázquez, Xx, pp. 229-259.

WebBer, Edwin J. (1958), "The Celestina as an arte de amores», Modern Philology, LV, 3, pp. 145-153. 
WebBer, Ruth House (1977), "Pedro Manuel de Urrea y la Celestina» en La Celestina y su contorno social. Actas del I Congreso Internacional sobre la Celestina, ed. M. Criado de Val, Madrid, Hispam, pp. 359-366.

Weissberger, Barbara F. (1983), "Authors, Characters and Readers in Grimalte y Gradissa", en Creation and Re-creation: Experiments in Literary Form in Early Modern Spain. Studies in honor of Stephen Gilman, ed. R. E. Surtz y N. Weinerth, Newark, Delaware, Juan de la Cuesta, pp. 61-76.

Ximénez de Urrea, Manuel, Penitencia de amor, ed. Domingo Ynduráin, Madrid, Akal, 1996. 


\section{NúÑEz RIVERA, Valentín, "Por arte se ha de regir el amor. El proceso de recuesta según Ximénez de Urrea», Celestinesca 30 (2006), pp. 89-109.}

\section{RESUMEN}

Penitencia de amor constituye un arte de amores en toda regla cuyas estrategias se muestran en la estructura dramática. El proceso de recuesta amorosa se conforma mediante el intercambio epistolar y los encuentros entre los enamorados. En ambos casos se trata de cuatro segmentos dramáticos, hecho que confirma el mecanicismo de las acciones. Ese determinismo viene impuesto, entre otras cosas, por el modelo de Celestina. No obstante, en el segmento final el castigo a medias que impone Nertano invalida las leyes de la tradición sentimental.

Palabras Clave: Penitencia de amor Ximénez de Urrea, artes de amar, Celestina, epistolaridad.

\section{ABSTRACT}

Penitencia de Amor can be considered a real art of love whose strategies are shown in its dramatic structure. The loving process is constitued by the epistolary exchanges and by the meetings among the lovers. In both cases, we are in front of four dramatic segments; a fact which confirms the mechanism of the actions. Such determinism is imposed by the pattern of La Celestina_. Nevertheless, in the last part, Nertano's half punishment invalidates the laws of the sentimental tradition.

KEY WORDS: Penitencia de amor Ximénez de Urrea, ars amatoria, Celestina, epistolarity.

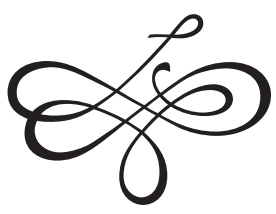


租 